\title{
La lengua en pedazos. \\ La experiencia de un proceso creativo teatral con la figura de Santa Teresa de Ávila
}

\author{
Andrea Pelegrí \\ appelegr@uc.cl \\ Ramón Gutiérrez \\ FACULTAD DE ARTES \\ PONTIFICIA UNIVERSIDAD CATÓLICA DE CHILE \\ rqgutier@uc.cl \\ Agustina Serrano ${ }^{1}$ \\ FACULTAD DE TEOLOGÍA \\ PONTIFICIA UNIVERSIDAD CATÓLICA DE CHILE
}

Resumen: El siguiente texto pretende dar cuenta del proceso creativo vivido durante el montaje de la obra La lengua en pedazos, del dramaturgo español Juan Mayorga, que tiene como protagonista a Teresa de Ávila. En el contexto de la celebración de los 500 ańos del nacimiento de la Santa, la compañía de teatro La Calderona -nacida al alero de la Facultad de Artes de la PUC- ha querido crear un montaje interdisciplinario, donde el teatro, la música y la teología, confluyen para dar vida a Santa Teresa y a sus enseñanzas. Pretendemos plantear aquí los temas principales que surgieron en la investigación escénica, así como las reflexiones religiosas y antropológicas suscitadas por la obra de Mayorga sobre los escritos de la Santa.

\footnotetext{
Agustina Serrano, antigua profesora asociada de la Facultad de Teología, participó a lo largo de todo el proceso creativo, en las actividades de mediación y en algunos de los ensayos. Fue la encargada de asesorar a Teatro La Calderona en la teología teresiana. Ayudó a toda la compañía a comprender profundamente el sentido de las palabras de Santa Teresa y el valor de su obra. Participó además en la etapa preliminar de redacción de este estudio, hasta el día de su fallecimiento el 29 de junio de 2015. Este artículo es a la vez fruto de su trabajo y participación en el proyecto, y un homenaje por parte de Teatro La Calderona a su arduo y apasionado trabajo con nosotros.
} 
Palabras clave: Santa Teresa de Ávila, Juan Mayorga, La lengua en pedazos, Compañía Teatro La Calderona

Abstract: The following paper seeks to explain the creative process of the theatre play La lengua en pedazos, by the Spanish playwriter Juan Mayorga, on Theresa of Avila. In the context of the celebration of the 500th anniversary of the Saint, the theatre company La Calderona-developed under the inspiration of the Faculty of Arts of the PUC-created an interdisciplinary mise en scène, in which theatre, music, and theology come together to bring Saint Theresa and her teachings to life. We intend to show the main issues that arose during the creative process, as well as the religious and anthropological reflections on occasion of Mayorga's work on the Saint's writings.

Key words: Saint Theresa of Ávila, Juan Mayorga, La lengua en pedazos, La Calderona Theatre Company

En el año 2015, España y la comunidad católica del mundo entero celebraron los 500 años del nacimiento de Santa Teresa de Ávila. Una serie de variadas actividades culturales y religiosas se llevaron a cabo, no solo para conmemorar tan magno evento, sino también para divulgar su palabra, vida y obra entre quienes la conocían menos. En el caso de Chile, la compañía Teatro La Calderona ${ }^{2}$, de vasta trayectoria y especialista en teatro clásico del Siglo de Oro español, decidió poner en marcha un ambicioso proyecto: crear una puesta en escena interdisciplinaria -que involucrara al teatro, la música y la teología- del texto La lengua en pedazos, del autor espańol Juan Mayorga (1965) y ganador del prestigioso Premio Nacional de Literatura dramática de Españaª . El texto de Mayorga pone como protagonistas a Teresa (encarnada por Sara Pantoja) y un Inquisidor (encarnado por Alexei Vergara), en el contexto de un acalorado debate entre ambos. El montaje resultante tuvo funciones en el Centro Cultural Gabriela Mistral durante los meses de mayo y junio

2 La compañía Teatro La Calderona nació en el año 2003, en el seno de la Escuela de Teatro de la Pontificia Universidad Católica de Chile. Fue fundada por Macarena Baeza de la Fuente, Sara Pantoja, Gina Allende y Verónica Barraza.

3 El proyecto pudo llevarse a cabo gracias al financiamiento otorgado por los fondos concursables de la Pastoral y de la Vicerrectoría de Investigación de la Pontificia Universidad Católica de Chile. Los títulos respectivos de los proyectos ganadores son: "Montaje obra teatral La lengua en pedazos: teatro, música y teología para los 500 años de la santa" y "Puesta en escena de La lengua en pedazos de Juan Mayorga, proyecto 500 ańos Santa Teresa”. 
La lengua en pedazos. La experiencia de un proceso creativo teatral con la figura de... 369

del 2015, con alta afluencia de público y acompañado de un caluroso recibimiento por parte de la crítica ${ }^{4}$. Además, se realizaron una serie de representaciones itinerantes de la obra, con una escenografía adaptada, en diferentes locutorios de claustros de Carmelitas en la Región Metropolitana ${ }^{5}$. Considerando el valor de Teresa en la teología católica y dada la ocasión de la celebración de su natalicio, el proyecto se vio acompañado también de una serie de actividades de mediación con los públicos (ensayos abiertos, conversatorios y breve material escrito expuesto en los programas de mano para acompañar la recepción de la obra). Además, otro pie forzado en el proyecto era construir un montaje que incluyera disciplinas externas al teatro mismo para dialogar con la obra: la música y la teología. Considerando la complejidad de los escritos de Santa Teresa, a pesar de su evidente importancia y pertinencia en el mundo actual, la presencia de la teología como disciplina en el montaje se vuelve fundamental para entender a cabalidad la relevancia teológica de Teresa. Asimismo, la música, que por lo demás siempre ha formado parte del trabajo de Teatro la Calderona, viene a dialogar con el trabajo actoral, tal como veremos más adelante.

El presente texto, más que elaborar hipótesis en torno a la vida y obra de Santa Teresa, o de analizar, desde un punto de vista teológico su legado actual, pretende más bien dar cuenta del proceso creativo detrás del montaje, del entramado entre teatro, música y teología, entre palabra, cuerpo, ficción y testimonio, que permitió finalmente concretizar en la escena, en carne y hueso, la figura de Santa Teresa, y algunos de sus escritos más bellos. Se trata de presentar una expresión a múltiples voces, para intentar describir, en toda su complejidad, el proceso de trabajo que culminó en las representaciones del montaje La lengua en pedazos. Es un relato subjetivo, situado en el espacio liminal entre la reflexión académica y la artística, entre una bitácora personal y un documento de

4 La lengua en pedazos se estrenó el día viernes 17 de abril de 2015 en GAM (Centro Gabriela Mistral). Dirección: Mario Costa. Asistente de dirección: Ramón Gutiérrez. Actores: Sara Pantoja, Alexei Vergara, Carola Munitiz. Viola da gamba: Gina Allende. Diseño integral: Catalina Devia. Asesoría teológica: Agustina Serrano. Mediación: Andrea Pelegrí Kristić. Espacio sonoro y producción: Macarena Baeza.

5 Los claustros incluidos en esta gira fueron: San José (Ñuñoa), Cristo Rey (La Florida), Santa María Madre de la Iglesia (Puangue), Jesús, María y José (Romeral) y Del Espíritu Santo (Los Andes). La realización de esta itinerarancia fue posible gracias al patrocinio del Vice Gran Canciller de la Pontificia Universidad Católica de Chile y la colaboración de la Dirección de Pastoral y Cultura Cristiana de la universidad. 
trabajo. Se trata de fragmentos, de retazos escritos que buscan dar sentido a un proceso artístico, explicar las motivaciones detrás del montaje y los procedimientos para dar vida a Teresa de Ávila en escena, desde el teatro, la música y la teología.

Para quienes no conozcan la obra, el texto teatral de Mayorga, a grandes rasgos, construye un diálogo ficcional entre Teresa y un inquisidor, quien va a buscar a la rebelde Teresa al convento que ha fundado fuera de la orden de la Encarnación, para juzgarla y obligarla a volver donde sus hermanas, so pena de ser castigada por la Santa Inquisición. Si bien no existen registros de este diálogo entre Teresa y su Inquisidor, Mayorga recupera gran parte de los escritos de la Santa -gracias a su condición de mujer escritora- para construir los diálogos de ambos personajes -no solo de Teresa- creando así una especie de "monólogo a dos voces", en el que Teresa dialoga consigo misma, con su alter ego, representado físicamente por el Inquisidor. Mayorga delega, a partir de un diálogo inteligente y agudo, la responsabilidad de reflexión en nuestras manos sobre los más variados temas presentes en la obra, como la fe, el amor incondicional, la profunda duda, el sentido de una vida dedicada al servicio, o incluso la muerte. Y esta multiplicidad temática no es en ningún caso artificial: Teresa en efecto vivió una vida en el camino de la oración, que se refleja con gran maestría en su obra de fundadora y en sus escritos, relacionando todo con el acontecer histórico y desde una comprometida visión eclesial. Asimismo, no fue tampoco una mujer alejada de las vicisitudes de la vida mortal: desde joven sufrió dolorosas enfermedades, que la acercaron desde temprana edad a la muerte. El texto del dramaturgo español rescata el lenguaje de Teresa, su fuerza y su gran fe -enfrentada de manera constante, sin embargo, a la duda- en Dios y en el mundo creado por él, desde la belleza de las palabras, las metáforas e imágenes evocadas tanto por la monja como por el Inquisidor mismo.

Uno de los elementos más interesantes, tanto del texto mismo como del proyecto de puesta en escena propuesto por Teatro La Calderona, consiste justamente en la vigencia del mensaje de Santa Teresa, mensaje que por lo demás trasciende al mundo eclesial o incluso católico. Tal como hoy propone el Papa Francisco, el mundo actual requiere una Iglesia más cercana a sus fieles, menos asceta y más compenetrada con la realidad y los problemas del mundo. En su carta al obispo de Ávila, y con motivo de las celebraciones en torno al natalicio de Santa Tere- 
La lengua en pedazos. La experiencia de un proceso creativo teatral con la figura de... $\mid 371$

sa, el sumo pontífice expresa: "Su experiencia mística [de Teresa] no la separó del mundo ni de las preocupaciones de la gente. Al contrario, le dio nuevo impulso y coraje para la acción y los deberes de cada día, porque también "entre los pucheros anda el señor [...]»". El mensaje de Teresa se vuelve entonces vigente, un mensaje lleno de amor y expresado desde una paradójica mezcla de humildad y coraje, humor y profunda seriedad. Su interés trasciende incluso la religión católica; poco importa que los espectadores sean católicos o incluso ateos, el mensaje en los escritos de Santa Teresa, y en particular las palabras rescatadas por Juan Mayorga y encarnadas en escena reflejan las dudas y cuestionamientos que atormentan a todo ser humano, sin importar religión, raza, género o condición.

Una de las ventajas de montar La lengua en pedazos dentro del contexto universitario, en especial en la Pontificia Universidad Católica de Chile, es la oportunidad de permitir que confluyan tres áreas -unas en apariencia más diferentes que las otras- dentro del proyecto: el teatro, la música y la teología. Además, el proyecto, que se origina en el contexto universitario, busca posteriormente salir de él, como una forma de conectar el mundo académico con el artístico y social fuera de la Universidad, una de las misiones principales de nuestra casa de estudios. Así, además de conectar a la academia con el Chile actual, el segundo objetivo de este proyecto fue trabajar el texto de Mayorga desde una perspectiva interdisciplinaria. Cuando utilizamos este término, lo entendemos desde la definición que da Tamayo y Tamayo: "conjunto de disciplinas conexas entre sí y con relaciones definidas, a fin de que sus actividades no se produzcan en forma aislada, dispersa y fraccionada". No se trata entonces de un enfoque transdisciplinar, en el que de cierta forma desaparezcan las disciplinas y sus especificidades, pero sí de tratar el mismo objeto desde las particularidades de cada área y aprovechando las herramientas que cada una pueda aportar. Así, si bien el teatro reunirá el resultado medular de la investigación, la música y la teología serán los puntos de fuga claves para el montaje. La música, que en el montaje se convertirá también en un actor más, será el ancla hacia el pasado, evocando al mundo interior y exterior de la Teresa del 1500. La teología,

6 Conferencia Episcopal Española, "Mensaje del Papa Francisco con motivo del V Centenario del nacimiento de Santa Teresa”. 15 oct. 2014.

7 M. TAmayo y Tamayo, Diccionario de la investigación cientifica. Limusa, México D.F., $2004,81$. 
por su parte, será el puente que nos ayude a mirar la vida, la obra y la espiritualidad de Teresa desde el pensamiento de la Iglesia contemporánea, para ayudarnos a actualizar su legado, estableciendo los puntos de contacto entre la propuesta del actual Papa Francisco y la visión de fe de la santa. El objetivo último de este trabajo interdisciplinario es sostener un diálogo verdadero y crítico entre las estructuras teológicas contemporáneas y nuestras visiones teatrales, musicales, filosóficas y literarias, desde el pensamiento teresiano, expresado tan bellamente en sus escritos.

Por lo tanto, y desde esta perspectiva, el elemento que acrisola las tres disciplinas es la palabra de Santa Teresa, rescatada a través de sus escritos por Juan Mayorga, quien usa el verbo teresiano para construir un diálogo entre la Santa y el Inquisidor. Este último no es sino una versión de ella misma, tal como mencionábamos anteriormente, su "alter ego", oficiando a la vez de reflejo y contraparte para cada uno de los argumentos de Teresa, una mujer excepcional, sobre todo en su tiempo, al atreverse a desafiar a la autoridad eclesiástica y patriarcal, siempre en la búsqueda de la verdad y la santidad más allá del ego y del éxito personal. En tanto reflejo, es el espejo que le hace dudar constantemente de sus pasos, de sus acciones, incluso de su fe. Es una duda casi filosófica que la empuja cada vez más allá en su camino, en sus reflexiones. Es desde su condición de mujer y monja que se atreve a escribir. Su obra no solo aporta a la teología, sino que además contribuye a la formación de la lengua castellana durante el Siglo de Oro español, uno de los periodos más fértiles en las letras y artes peninsulares. En su autobiografía, titulada El libro de la vida, afirma que: "Era tan en extremo lo que en esto me embebía, que si no tenía libro nuevo, no me parece tenía contento" ${ }^{8 "}$ su nueva vida la califica como que "es otro libro nuevo". Su manera de escribir según habla ("iré hablando con ellas en lo que escribiré"10), nos remite por un lado al texto y también -y sobre todo- a tratar de ir "más allá del texto". Teresa escribe por necesidad, para compartir la gracia desbordante que la somete. Le gusta escribir, ama la literatura, escribe casi compulsivamente. Sin medios y a deshora, se cuentan más de 18.000 páginas escritas de propia mano. Es la única de quien se conservan sus originales, gracias al celo de las Carmelitas, quienes protegieron esa obra como si de un

\footnotetext{
8 T. Álvarez (Prep.), Santa Teresa. Obras Completas, 16 ed., Burgos: Editorial Monte Carmelo 2011, V. 2, 1.

9 T. Álvarez (Prep.), Santa Teresa ... V. 23, 1.

10 T. Álvarez (Prep.), Santa Teresa ... M. pról. 4.
} 
La lengua en pedazos. La experiencia de un proceso creativo teatral con la figura de... $\mid 373$

tesoro se tratase; ni de Cervantes fue posible mantener los manuscritos ya que en la imprenta acababan en el basurero.

No es en vano entonces que la propuesta literaria teresiana sigue teniendo una excelente y prodigiosa recepción; sus escritos se venden en los quioscos junto con el diario y los bestseller. Su obra es actual porque nos habla de un ser humano dialogante con su entorno y así va construyendo su identidad al estilo del Jesús del Evangelio, quien centra su vida, proyecto y mensaje en el único amor que gracias al Espíritu se despliega en amor a los hermanos y amor a Dios. Es así como Teresa, en tanto amante de las letras y la literatura, ha tenido una recepción temprana debido a su cercana relación con el pensamiento de su época y a la capacidad para la conversación; dialoga con todos, desde los teólogos hasta el Rey. Sus obras encuentran acogida y se publican, porque se sustentan en la vida de cada ser humano.

Así, la riqueza del lenguaje utilizado en sus escritos y rescatado por Mayorga, las metáforas, los conceptos, las reflexiones que surgen sobre la vida humana, Dios, la religión y el lenguaje mismo sirven así de partitura musical para el trabajo vocal y también para el trabajo musical de la puesta en escena propuesta por La Calderona; a lo largo del montaje, Gina Allende, quien se encuentra presente a lo largo de toda la acción, acompañando a Sara Pantoja y Alexei Vergara, intercala fragmentos musicales, ejecutados con su viola da gamba ${ }^{11}$, con los diálogos y monólogos de los personajes. No se trata entonces de música ambiental, que pretende acompañar o resaltar estados anímicos; se trata más bien de un instrumento más, sumado a los cuerpos de los actores, que viene a dialogar también con ellos. Se vuelve, de hecho, tal como lo precisa la misma Allende, en "un actor más", tan involucrado en la acción como Pantoja o Vergara. Durante el proceso de creación, los diferentes fragmentos musicales, algunos previamente existentes, otros creados por Allende, se van insertando durante los ensayos, según las necesidades de la puesta, y no necesariamente de antemano. O sea, si bien Allende llegaba a los ensayos con ciertas propuestas, estas se deconstruían según las necesi-

11 Instrumento perteneciente a la familia de los cordófonos de arco, muy utilizado entre los siglo XV y XVIII en Europa. En ese sentido, el timbre y la cualidad del sonido que produce el instrumento es también un signo de remembranza de la época en la que vivió Santa Teresa, entregándole así al montaje una atmósfera que remite al espectador a los tiempos en los que se desarrollaría la acción. 
dades surgidas en escena, incluso improvisando fragmentos; en otras ocasiones, Mario Costa (director de la puesta) pedía otros fragmentos si era necesario (generalmente ciertas piezas que fuesen contemporáneas a Santa Teresa, a partir de la experticia musical de Allende). Así, las decisiones finales se toman luego de experimentar en el diálogo entre las piezas musicales y las palabras y cuerpos de los actores. Es solo durante el proceso de ensayos, escuchando las palabras y sintiendo los gestos y acciones surgidos de los cuerpos, que la música se intercala entre las escenas, creando el entramado musical (compuesto por la viola, la musicalidad de las palabras y los silencios) de la puesta. Es por ello que la presencia de Allende en escena es constante, no solo en los ensayos, sino que en el montaje mismo. La intérprete no abandona la escena, aun cuando esté (solo) escuchando los diálogos entre Vergara y Pantoja. Es así como la música no es nunca un simple acompañamiento o un adorno para embellecer. La música se vuelve teatral en un sentido actoral; interpreta, dialoga, viaja, acompańa, sirve de contrapunto o por el contrario exacerba las emociones. Se involucra intensamente con la acción y los otros actores. Así como el lenguaje musical existe a través de estas piezas interpretadas por Allende, la palabra del texto se vuelve también música, mientras que el sonido de la viola se torna acción, lo que deja leer, de manera más completa y certera, las palabras de Teresa (y de Mayorga).

Cada función, cada nueva representación implica además un espacio de búsqueda nuevo, prolongando ante el público los descubrimientos surgidos durante el tiempo de los ensayos. Gina Allende comentaba en uno de los conversatorios con el público durante el periodo de funciones en GAM, que en una ocasión, luego de una función, Sara Pantoja le había comentado que para ella la viola da gamba representaba la enfermedad, en uno de los momentos de la obra en el que Teresa describe al Inquisidor los fuertes dolores que la aquejaron cuando joven. Así, la pieza interpretada por Allende permitía a la actriz tener un estímulo concreto y real para gatillar las imágenes y emociones necesarias en la interpretación de ese texto, acompañando a sus propios recuerdos y memoria emotiva, como veremos más adelante. Eso es un claro ejemplo de cómo la música es un actor más, como si fuese otro ser humano respondiendo a sus palabras, sirviendo de espejo y de reacción a las acciones de la actriz, creando el espacio necesario para que ese monólogo, ese recitativo en apariencia solitario, se convierta en diálogo y se llene de vida. 
La lengua en pedazos. La experiencia de un proceso creativo teatral con la figura de... $\mid 375$

Además de la música y la teología, que de cierta forma engloban a todo el proceso, está la tercera disciplina -quizás dominante- del proyecto: el teatro. Si bien el proyecto se autodefine como interdisciplinario, y por lo tanto, sin un elemento que domine necesariamente al otro, de cierta forma es el ámbito escénico el aspecto troncal del trabajo, el que reunirá a las demás disciplinas en el punto central que es la representación de la figura de Santa Teresa de Ávila. La coexistencia e integración del teatro, la música y la teología representaron para nosotros una serie de desafíos. Es cierto que la música y el teatro van muy de la mano, en tanto ambas son artes. Esta relación, en el caso particular de Teatro la Calderona es aún más evidente, ya que desde los inicios de la compañía se ha buscado la interacción armónica y constructiva de ambas disciplinas. Aparentemente, las grandes diferencias se encuentran entre las artes y la teología. Sin embargo, aun cuando la relación entre estas tres disciplinas, en especial entre el teatro y la teología, pueda parecer en la actualidad un tanto forzada, incluso inexistente, basta con revisar someramente la historia del teatro y la música occidentales para ver cómo han estado íntimamente ligados. Muchas de las piezas musicales más sublimes del canon occidental se compusieron para acompańar ceremonias litúrgicas, o fueron compuestas por seres muy cercanos a Dios. Y es que pareciera que los misterios de la vida y la muerte, de Dios y de la humanidad logran expresarse de alguna forma con las herramientas del arte, a través de la música, de la palabra encarnada, del gesto creador.

Sería ingenuo no obstante olvidarse de precisar que la relación entre teatro y teología, o más ampliamente, entre teatro y religión católica, es un poco más compleja. Ya sea desde la oposición máxima, la desconfianza o el apoyo mutuo, ambas esferas se han encontrado para producir, a pesar de su contradictoria relación, algunas de las obras más hermosas de la humanidad. Si bien, durante la Temprana Edad Media, luego de la Caída del Imperio Romano de Occidente, algunos emperadores impulsaron una serie de medidas en contra del teatro (como restringir severamente los tipos de representaciones a realizarse, o incluso alejar a los actores de la esfera pública), posteriormente durante el apogeo de la religión católica en Europa surgieron nuevas manifestaciones teatrales, como los misterios, milagros o autosacramentales, que se servían justamente del arte de los histriones para poner en escena momentos de la vida de Jesús, convirtiéndose en un medio de evangelización y vulgarización del mensaje católico entre las masas. 
Es posible ir incluso más allá de la religión católica para encontrar las relaciones entre teatro y rito, sin pensar necesariamente en una religión específica. Por el hecho de tratarse de un encuentro entre seres humanos, en el que se repiten ciertas acciones en un espacio-tiempo que de cierta manera escapa del tiempo cotidiano, hay evidentes relaciones a establecer con el rito. Tal como explicita Jorge Dubatti en torno al acontecimiento convivial que implica el teatro, "el convivio marca el reencuentro en una subjetividad ancestral de unidad ${ }^{12}$ ".

Con el montaje de La lengua en pedazos, Teatro La Calderona muestra cómo es posible generar una simbiosis fructífera entre el teatro, la música y la religión, aprovechando el contexto de la obra de Mayorga, pero a la vez yendo más allá de un mero trabajo de evangelización o de tematización de lo religioso. A través de las palabras de Santa Teresa, es posible por un lado reflexionar sobre su figura y su mensaje (como hemos explicado anteriormente), pero también entender la dimensión de lo religioso y de lo místico más allá del texto, en el cuerpo de los actores (y la intérprete de viola da gamba, que es una actriz más) y en el encuentro entre estos y los espectadores, en aquel momento ritual del espectáculo. Esta dimensión se vuelve aún más patente si pensamos en las funciones realizadas en locutorios de los claustros de Carmelitas, en donde las espectadoras van entre las seis y las dieciséis por función, y donde la pobreza grotowskiana ${ }^{13}$ (su ideal de teatro pobre en donde solo existen actores y espectadores en un espacio) es llevada a su máxima expresión: no hay escenografía, ni iluminación, ni artificios. Solo los cuerpos de los actores, y sus voces a través de las rejas, en un momento convivial que, como expresa la anterior cita de Jorge Dubatti, nos lleva a un momento ancestral previo al lenguaje.

12 J. Dubatti, Filosofía del Teatro II. Cuerpo poético y función ontológica, Atuel, Buenos Aires, 2010, 35

13 Jerzy Grotowski (1933-1999), importante director polaco, fundador del Teatro Laboratorio, promulgaba un "teatro pobre", en el que los recursos técnicos y los artificios desaparecieran completamente para dar cabida solamente a los actores y al encuentro entre estos y los espectadores. En muchos aspectos, varias de las ideas de Grotowski se encuentran presentes en el montaje de La lengua en pedazos, como la relación entre los actores y los espectadores, y la "pobreza" de los medios técnicos -o más bien la simpleza de estos- para posibilitar este encuentro único y ritual, tan cercano de la religiosidad. 
La lengua en pedazos. La experiencia de un proceso creativo teatral con la figura de... $\mid 377$

En un conversatorio entre el equipo creativo y los espectadores del día 3 de mayo de 2015, después de una función de la obra en el Centro Cultural GAM, una espectadora comentó, respecto a su experiencia con la puesta: "Yo vi a Dios a través de la obra". Entonces es cierto: si bien esta no es una obra religiosa, ni historicista, ni menos aún teológica, tal vez sea una obra que busca a Dios, de alguna manera, en algún sentido. Algo hay en ella que no permite mirarla sin pensar en algo más que la fórmula común del espectáculo habitual, "burgués", si pensamos en la crítica de las vanguardias de inicios del siglo XX.

Teatro La Calderona pretende buscar compulsivamente la belleza. Pero el texto de Juan Mayorga nos ha hablado de tal forma que ha resultado en la búsqueda obligada de una belleza diferente a la que acostumbramos todos. Esta belleza no es el resultado de la articulación armónica de signos, de recursos estilísticos, de medios artísticos y de elementos sensoriales; esta belleza viaja por otra dimensión, pertenece a otra fuente, se comporta de modo distinto y se vale del mundo de lo sensible solo para potenciar su manifestación. Desde esta perspectiva, se hace forzoso señalar que, pese a citar a cada momento, de manera textual -aunque no condescendiente- a Teresa de Ávila, la obra de Mayorga no es una recopilación inocua de frases fascinantes, ni es una antología poética o teológica de la primera Doctora de la Iglesia Católica. La lengua en pedazos es, en más de algún modo, un texto de naturaleza volcánica, amenazante, feroz; es "políglota" por excelencia, pues se pasea sin problemas desde el lenguaje del espíritu al de la razón, del lenguaje de la fe al del ateísmo, del lenguaje del amor al de la revolución; está diseñado para llevar al director, al actor, al público a ser parte de un "espectáculo de sedición", como dijera Antonin Artaud, de una confrontación consigo mismo, de un desenmascaramiento y autodesenmascaramiento rebelde a partir de la propia rebeldía de una monja sin parangón que se desenmascara frente al espectador, frente a su inquisidor y, sobre todo, frente a sí misma.

En este sentido, se han alineado ejercicios de naturaleza diversa y en los que participan, de manera análoga y afín, todos los estadios del fenómeno teatral: el referente real que deviene personaje, el personaje mismo de la ficción, el autor del texto, el director del montaje, la diseñadora, los actores, la viola da gamba y las notas que de ella surgen, el público. Esta comunión de voluntades concertadas y de acciones cómplices ha generado las condiciones para que se establezca un viaje trascendente y cargado 
de sentido que nos ha llenado de satisfacción y que deja en evidencia el parentesco de este proceso teatral con algunas de las ideas más notables del teatro de Jerzy Grotowski, bajo cuya luz quisiéramos mirarlo. No porque este proceso se haya conducido desde sus predicamentos, sino porque estos últimos podrían llegar a explicar, contener y vincular una serie de decisiones y acciones -conscientes o inconscientes- que conforman la experiencia de este montaje, desde su origen hasta su recepción.

El ejercicio de auto-confrontación al que Juan Mayorga somete a su personaje, al poner a Santa Teresa frente al Inquisidor es de una sugerente resonancia con el concepto de shock que pregonara Grotowski en su Teatro Laboratorio. Cuando hablamos de este shock debemos entenderlo en las cuatro líneas en que el director polaco lo describe en función del trabajo actoral: primero, tener que superarse a sí mismo ante un obstáculo; segundo, tomar conciencia de sus propias evasiones, trucos y clichés; tercero, estar conscientes de sus propios recursos; y cuarto, preguntarse la razón de ser actores. Si lo analogamos al recorrido de la protagonista, para Teresa es claro y permanente el primer aspecto, y en la acción de la obra toma la forma de un autointerrogatorio para dejarnos ver esa lucha. El segundo punto es forzado y llevado al extremo por el rol del Inquisidor: "Al examinar vuestros pasos, los juzgaréis como yo los juzgo 14"; "Indaguemos juntos cuáles fueron esas cárceles de las que hubo de sacaros el Señor ${ }^{15 ” ; ~ “ ~ ¿ N o ~ s e r a ́ ~ q u e ~ d u d a b a i s ~ s i ~ v u e s t r a s ~ v i s i o n e s . . . ~ e r a n ~}$ ilusión?16"; "Incluso a vuestro confesor tuvisteis engañado ${ }^{17 " ; ~ " A ~ m e n u-~}$ do se llama espíritu a lo que es desorden ${ }^{18 ” ; ~ “ ¿ N u n c a ~ d u d a ́ i s, ~ T e r e s a ? ~}{ }^{19 ” ;}$ "Cuánto miedo a vivir bajo ese ansiar la muerte. Cuánto miedo a ese cuerpo que queréis encerrar y amortajar ${ }^{20 "}$. Sobre el tercer punto se reconstruye la certeza de Teresa; la reafirmación consciente de su debilidad deviene fortaleza y, más que el amor mismo, es la duda la que confirma el rumbo que ha tomado. Sobre el cuarto cuestionamiento, aparece en la Santa, una vez más, el amor y el deseo de servir y obedecer a la voluntad

14 J. Mayorga, La lengua en pedazos, texto inédito, versión utilizada para el montaje, 2015, 3.

15 J. Mayorga, La lengua ... p. 5.

16 J. Mayorga, La lengua... p. 20.

17 J. Mayorga, La lengua... p. 20.

18 J. Mayorga, La lengua... p. 22.

19 J. Mayorga, La lengua ... p. 25.

20 J. Mayorga, La lengua... p. 25. 
La lengua en pedazos. La experiencia de un proceso creativo teatral con la figura de... $\mid 379$

de quien ama, como las razones claves para desempeñar este rol, para ser protagonista de su vida religiosa y actriz de su propia obra.

Teresa pareciera encontrarse con dos elementos conflictivos de su ser más íntimo -el recuerdo del propio vía crucis moral que su vida representa y su duda permanente- en contraposición a su amor incendiario a un Dios cercano y manifiesto. "Mi vida ha sido de muchos trabajos del alma. Fuera de eso, no veo en ella nada que merezca recordarse ${ }^{21}$ ", responde Teresa a la orden del Inquisidor de repasar su biografía a fin de juzgarla como él la juzga.

Ahora bien, ¿cómo "encarnar", cómo "interpretar", cómo "representar" o cómo "actuar" este proceso de shock propuesto por Juan Mayorga, dando cuenta de la envolvente y ardiente pasión con que esta monja, tan Santa como mujer, lo habría vivido frente a su Inquisidor o en la soledad de su celda, frente a sí misma? ¿Qué recursos, qué mecanismos podrán aproximar a nuestros actores a esa vehemencia, a esa furia, a ese amor, a ese fervor, a esa fe y a esa duda? Querámoslo o no, conscientes los actores o no, deliberadamente guiado desde la dirección o no, el mismo proceso de encuentro consigo que se cuenta en la obra se encarna en los actores para volverse un proceso personal, un propio shock.

Por lo mismo, el gran tema del trabajo actoral para este montaje fue la claridad, el entendimiento -desde varias aristas- de lo que los personajes hacen, de lo que buscan, de lo que dicen, de lo que callan. Ello en conjunto con una investigación detallada sobre el contexto geográfico temporal que contenía la acción y los robustos pilares ideológicos, religiosos y políticos que la llenan de sentido y contingencia. Es allí donde la asesoría de un experto en teología del proyecto es fundamental. Aun cuando el montaje no pretenda ser un ejercicio teológico, sino más bien religioso, o espiritual, si se quiere, el hecho de poder contar con un experto en el área -y específicamente de la teología teresiana- nos ayuda a conectarnos en profundidad con un mundo que desconocemos. Este apoyo busca no solo clarificar las palabras en apariencia oscuras de Teresa, sino que también permite entender el contexto en el que se despliegan, las relaciones de fuerza entre lo femenino y lo masculino, entre el poder patriarcal y matriarcal en la Iglesia. Desde esta perspectiva y gracias a la investigación realizada, necesaria para un montaje de esta

${ }_{21}$ J. Mayorga, La lengua... p. 3. 
naturaleza, no fue particularmente difícil darle forma lógica a las escenas, porque la dramaturgia de Mayorga abre muchísimas posibilidades de acción desde la claridad con que entrega al actor los objetivos y causas que persiguen y defienden los personajes. La relación de estatus es igualmente legible con un par de lecturas de la obra.

El problema comenzó a presentarse cuando, al intentar profundizar en las escenas y darles un sentido más particular, algunos textos empezaron a delatar cierta distancia que los actores tenían con determinados conceptos e ideas: hablar del infierno y del demonio se hacía muy difícil, las imágenes eran vagas y las palabras sonaban a caricatura o a arcaísmo. Hablar de Dios con la convicción de cada uno de los dos personajes, desde su manera particular de concebirlo, también era un desafío tremendo; más aún, hablar de una experiencia mística como la de Teresa, de un Dios que le habla, se le representa, la escucha. Hablar de los principios morales y éticos que la Santa defendía con un ímpetu inabarcable también era un tema complejo; "¿cómo decir "viviremos de limosnas" sin sonar a cliché o a eslogan?”, se preguntaba Sara Pantoja. Hablar de su repudio a los monasterios abiertos, como también hablar del repudio al género femenino o al mundo judío converso, por parte del Inquisidor, era muy complicado fuera de sus parámetros ideológicos. Finalmente, hablar de la terrible enfermedad que suspendió su vida por cuatro días y que le imprimió en el cuerpo secuelas enormes, así como hablar de la crítica relación que Teresa mantuvo siempre con sus acciones pasadas, se instaló como un desafío intenso, muy exigente y en extremo comprometedor. Estamos hablando de ideales sublimes, de tragedias personales difíciles de entender -menos aún de sentir- si no se han vivido, de experiencias místicas y religiosas de envergadura que no todos los seres humanos hemos tenido la oportunidad de experimentar.

$Y$ es que para entrar en la protagonista hay que entrar en el cuerpo propio y en la vida propia; de otro modo se vuelve superficial, artificioso. Teresa es toda ella experiencia, toda ella es cuerpo y espíritu vividos en la máxima compenetración. No predomina la mirada teórica, ni intelectual en lo que ella cuenta y en lo que ella defiende. En Teresa hay marcas de muchos tipos, impresas física, mental y espiritualmente. Por ello, no fueron solo los temas teológicos los que demandaron a los actores aproximaciones más allá de la comprensión intelectual. Si, por un lado, la experiencia del infierno que narra la obra de Mayorga es de una sensorialidad tan penetrante que pareciera ser que todos hemos accedido 
La lengua en pedazos. La experiencia de un proceso creativo teatral con la figura de... $\mid 381$

a ese lugar, que compartimos ese recuerdo, también la narración de la enfermedad de corazón que sufrió la Santa en su juventud es de una crudeza sensitiva que no merece, si bien pudiera resistirlos, artificios actorales fabricados. Es en este sentido en que la exigencia del recorrido del personaje por los momentos más álgidos de su vida parece conducir a la actriz a un repaso, en principio inconsciente, de su propia biografía para hacer justicia a las palabras que debe articular, para encontrar el lugar más pertinente desde el cual revivir aquello que le pertenece a una mujer excepcional hasta en el acto de haber, prácticamente, resucitado. Y no es impropio decir que, para este acto de memoria, la propia experiencia de la actriz es, además de evocada, puesta al servicio del relato teatral. Algunos de los más enraizados recuerdos de una importante enfermedad que la actriz viviera - por hermosa coincidencia- a la edad misma del mal de Teresa y con síntomas en común, estarán impresos en la memoria muscular que articula la narración física del padecimiento de la Santa. Las palabras de la protagonista, "mi enfermedad fue tal que el cuerpo teme que el alma haga memoria", antes de adentrarse en el recuerdo, son una antesala perfecta para verbalizar el ineludible nexo de la escena con el recuerdo privado de la actriz. Ciertos gestos, reminiscencias a posibles movimientos, reacciones, contracciones de la experiencia real, aparecen sistemáticamente en el trabajo de Sara Pantoja, como trayendo al presente un dolor que no pertenece solo al personaje histórico ni al de la obra, sino también a la actriz.

Del mismo modo que la pieza escogida por la violista para dialogar con el relato textual en ese momento particular del texto provoca en dicha intérprete una conexión muy potente con un recuerdo familiar, el cual, en resonancia con la experiencia de la actriz y las palabras de Teresa, participa de una comunión de inexplicable poder evocativo y generador de sentido. Si bien el camino por el cual el director llevó a los intérpretes no buscaba esta indagación autobiográfica, ni se intentó generar cruces ni puentes entre el texto y la propia intimidad, pareciera ser que el carácter de la obra, sus temas y su planteamiento dramatúrgico, fueron suscitando, espontáneamente, este camino en los actores, en mayor o menor grado de profundidad, dependiendo de la escena puntual, el texto específico o la tendencia de cada actor a entrar o mantenerse fuera de tal o tal tema de su intimidad.

Sin embargo, no todos los vínculos que se generan entre el actor y la obra son resultado de la remoción de la memoria. Muchos de los 
momentos de este auto-examen de Teresa y su proceso de duda se vinculan a una auto-percepción actual de los intérpretes; bien al presente del proceso de búsqueda de la obra, bien al momento presente de la escena misma. Aparece en un punto la duda y la fe de cada uno de los actores; el significado del amor en sus propias biografías, su modo de vivir la fe o la convicción desde su propia opción, desde su vocación, desde su misión, si se quiere poner en términos pastorales. Con ello, aparece el enfrentamiento a los propios miedos y a las propias certezas del mismo proceso; se hace presente también esa síntesis de la vida que comporta estar en escena y ejercer el oficio. Se vienen las dificultades encima y aparecen los cuestionamientos, las inquietudes, las debilidades. El actor debe enfrentarse a esos elementos, para superarlos. Se homologa así nuevamente la vida del actor con la de un monje, metáfora tan usada y trabajada por el mismo Grotowski, quien veía en el actor la búsqueda de un asceta, que en vez de llenarse de artificios mal llamados teatrales, se va despojando poco a poco de toda superficialidad, como si de capas se tratase, para acceder a una interioridad libre, pura, de forma muy similar a como Teresa entendía la vida monacal en el convento fundado por ella misma.

La duda del actor se unifica con la duda del inquisidor y ambos parecen viajar juntos por esas palabras y por esos procesos. El actor parece encontrar una manera de canalizar su duda a través de la conducta de su personaje y, en el sentido inverso, parece entender cómo alimentar el viaje de su rol con la experiencia personal de su incertidumbre como intérprete. La duda de la actriz queda yuxtapuesta, tal vez superpuesta a la duda religiosa. La Santa se pregunta acaso obra por amor a Dios o por vanidad y las intérpretes de la obra comparten ciertas preguntas: “¿Esto que estoy haciendo es verdaderamente honesto y coherente? Dudo de mí, creo mucho en esto, pero no sé si lo que hago porta esa ofrenda que quiero entregar. $\mathrm{Y}$ esa duda ¿̇responde realmente a la necesidad de salvaguardar el acto de verdadero sacrificio o acaso responde más a la necesidad del correcto cumplimiento que el ego invoca con desesperación? ¿Estoy escuchando a quien habla en escena o estoy yo hablándome a mí misma? ¿Es mi propia voz la que oigo o estoy abierta a recibir?”.

Esta calidad de cuestionamientos despierta particular interés para la correspondencia que buscamos entre el proceso de la obra con la función del teatro grotowskiano hacia la figura del propio actor: un trabajo actoral de "nuevo nacimiento", que trasciende al campo de la acción y se instala en el terreno de la persona, en el ámbito humano de renovación, 
en un crecimiento más profundo y radical. Detengámonos entonces en el paralelo entre este proceso de montaje y las bases del teatro grotowskiano para ahondar en cómo la naturaleza académica y la búsqueda interdisciplinaria de Teatro La Calderona parecen desafiar los principios de pobreza, despojo y vacío del polaco. Para este último, el teatro debe prescindir del eclecticismo, no preciarse de ser una amalgama de las otras artes y solo fundarse en la relación entre el actor y el espectador. Condena tajantemente al teatro que busca ser una síntesis de las otras disciplinas, tachándolo de cleptómano, híbrido, acumulador compulsivo y parásito.

En La lengua en pedazos, como en cada uno de sus montajes, Teatro La Calderona hace gala de un uso integral de la visualidad y la música: construye la imagen con especial cuidado, se vale de la luz para instalar con más fuerza el espacio, el tiempo y la poesía, da al sonido de la viola da gamba un espacio dramático y expresivo muy profundo y en notable relación con el trabajo actoral y el texto mismo, conformando parte más bien de un espacio sonoro total. Pero la gran particularidad del crisol artístico que conforma esta obra es la total disposición de todos los elementos extra-actorales al servicio del trabajo del actor y, con ello y más importante aún, al servicio de la transmisión del texto y al viaje al que este invita. Esto muy por sobre la pretensiones estéticas y el acaparamiento de recursos que Grotowski despreciara, puesto que en la propuesta del montaje pareciera hacerse extensivo el trabajo del actor a cada uno de los demás estadios de la puesta en escena: la música habla a través de una intérprete que participa y alimenta la acción, las piezas escogidas dialogan con la búsqueda de los actores, se cruzan, resuenan, se replican, se deconstruyen o hablan cuando el actor solo puede callar. La música aparece como el espacio de libertad para seguir "hablando" sin palabras cuando los personajes llegan al límite humano en que "no podemos hablar de lo único que importa". La luz es la puesta en el espacio de una sugerente ambigüedad que desestructura el tiempo y la dimensión realista del espacio para permitir al público y al actor acceder a procesos más complejos de recorrido a través del texto, sin resguardar la raíz lógica de la escena, sino las dimensiones trascendentes que ella propone, tal vez un camino hacia aspectos más espirituales.

El estreno de La lengua en pedazos nunca se concibió como la primera función de muestra de un espectáculo resuelto y acabado, cuyo fruto íntegro debía ser contemplado por el público desde su rol de consumi- 
dor cultural. Ni se asumió tampoco la labor predicadora ni profética; esta obra no es moralista ni catequista. La llegada al estreno con muchas dudas y procesos inacabados son parte del riesgo que corre la compañía al involucrarse con los intersticios más profundos del texto. No existe la premura por mostrar un resultado último, porque el resultado se lograba, al fin, en la experiencia del espectador; existía así la urgencia por compartir. No hay un ánimo de enseñar, porque apenas logramos enfrentarnos a los inmensos discursos de Teresa: existe más bien el deseo de aprender. A través de este trabajo similar al de un monje, es posible acceder a esa verdad que cada uno de nosotros lleva consigo. Es la eliminación de las máscaras que nos cubren para encontrar esa verdad profunda. Lo planteado por Grotowski no es más que una manifestación elaborada, luego de años de arduo trabajo, de aquellos ideales planteados por Antonin Artaud en su teatro, en particular en su conocido texto El teatro y su doble. Un teatro más allá de las ideas políticas o sociales, del logos, un teatro de lo universal, cercano al ritual, a lo religioso, a lo místico. En el caso de La lengua en pedazos, es a través de ese logos, de esa palabra, que se accede a esta experiencia religiosa que parece escapar al lenguaje y que permite en los espectadores, tal como se manifestaba durante el conversatorio, "ver a Dios". Esta experiencia fue intuida por el equipo de trabajo desde el principio, pero no se volvió evidente sino hasta el momento en que realizamos la gira por los diferentes claustros en la Región Metropolitana. En esos espacios despojados, en donde estábamos cara a cara con aquellas quienes encarnan día a día el legado de Santa Teresa, entendimos el propósito último de este proyecto, más allá del GAM, más allá de la investigación, más allá del proyecto en cuanto tal.

Así, la interacción entre teología y teatro-música permite, en un primer tiempo, intentar descifrar desde lo racional, desde la lectura, la investigación y la comprensión del contexto y de su valor teológico, los escritos de Teresa, las ideas, metáforas e imágenes que estos vehiculan. No obstante, a medida que comienza el proceso de encarnación y de puesta en escena, a medida que esas palabras de un otro se convierten paulatinamente en las palabras de los actores, en que las melodías de los fragmentos musicales se funden con las notas emanadas de las voces de esos actores, construyendo una sola gran partitura, es cuando el aspecto religioso del proyecto llega a su apogeo e involucra también las sensaciones, las emociones relacionadas con esas palabras sublimes. 
La excusa, si se quiere usar ese término, para montar La lengua en pedazos, fue la ocasión de las celebraciones que se llevaron a cabo en todo el mundo católico por los 500 años de su nacimiento. Esa excusa, no obstante, se volvió en la oportunidad de no solo rescatar el legado de una mujer extraordinaria, plurivalente y única -gracias además a la habilidad dramática de Juan Mayorga, en su selección de textos de Santa Teresa así como en la manera de articularlos en su obra, con su propio lenguaje- sino también de entender desde la escena el valor y el poder de la palabra y su relación con el misticismo y el catolicismo. Lo interesante de este rescate, además, es que se realiza a la luz de la contemporaneidad, desde las problemáticas actuales, en un mundo progresivamente más alejado de lo religioso o, por el contrario, que ha exaltado a Dios hasta el fanatismo, en cualquiera de sus formas. Se trata de entender el legado de Santa Teresa desde una articulación contemporánea, desde la mirada del hoy, desde una Iglesia Católica enfrentada a cambios sustanciales en sus cimientos. No solo en términos de contenido (la teología teresiana), sino también de forma (la importancia dada a la palabra en la escena).

La figura de Teresa presenta de una manera nueva las dimensiones fundamentales de la fe cristiana y católica. La relevancia teológica de su pensamiento se pone de relieve en la imagen de Dios que nos regala en íntima unión con su concepto de ser humano, y ambos en el ámbito de la comunidad. Teresa propone así la vuelta a las fuentes y en eso coincide con la propuesta renovadora del Concilio Vaticano II. "En la historia acontece permanentemente el retorno al Jesús histórico; y una de esas épocas culminantes es la de Teresa..., hay un resurgir antropológico que despierta un movimiento personalista y de recuperación de lo bíblico". El Dios encarnado en el Jesús histórico del evangelio que vive en un tiempo histórico y en un lugar determinado, le hace decir a Teresa: “¡Entre pucheros anda Dios!".

Algo similar ocurre con la obra, con el lenguaje (verbal y no verbal) que pretende ir más allá del texto para encontrarse con otro, el espectador, en una relación pura y verdadera. La palabra vela y devela lo inefable. El actor/actriz desaparece en el lenguaje musical y verbal y solo queda en el escenario la palabra, aunque sea en pedazos. Esa palabra, que puede entenderse como mera racionalidad, puede ser también reveladora de un rico mundo interno, de una verdad, de una interioridad tal como la entendía Grotowski, que se revela a los espectadores en un encuentro 
ritual, casi místico. Teresa se encarna en la actriz/actor en un proceso de anonadamiento y abajamiento; la actriz/actor es la mediación que transparenta el mensaje. Esto es la esencia del testimonio que remite al sacrificio inherente a toda representación de la vida. Es en estas metáforas, a través de estas paradojas, entre estos viles pucheros por los que anda Dios, en que es posible encontrarse con la luz de lo divino. Entre pucheros anda Dios, pues también entre actores, entre teatros, entre piezas musicales, se nos aparece. 